\title{
A questão da autoria no filme documentário e o caso Jean Rouch: uma perspectiva de análise ${ }^{1}$
}

Sandra Straccialano Coelho ${ }^{2}$

1 Trabalho apresentado no seminário temático "Ciências sociais e cinema: metodologias e abordagens de uma pesquisa interdisciplinar", do XIV Encontro da Sociedade Brasileira de Estudos de Cinema e Audiovisual (Socine), ocorrido em Recife, em 2010.

2 Doutoranda em comunicação e cultura contemporâneas na Universidade Federal da Bahia (UFBA), mestre em multimeios pela Unicamp e bacharel em letras pela mesma instituição. Membro do Laboratório de Análise Fílmica e do Núcleo em Análise do Cinema Documentário (UFBA). Atualmente desenvolve pesquisa sobre a narrativa na etnoficção de Jean Rouch. sandrixcoelho@gmail.com 


\section{Resumo}

O problema da autoria é difícil de abordar nos estudos cinematográficos e, sobretudo, no estudo do documentário. Esse artigo propõe o modelo teórico do campo de produção cultural desenvolvido pelo sociólogo francês Pierre Bourdieu como abordagem especialmente interessante para essa questão. Primeiramente, discutem-se alguns dos principais desafios e problemas teóricos relacionados à autoria no documentário. A seguir, por meio da análise da posição autoral do etnógrafo e cineasta Jean Rouch, demonstra-se, brevemente, o caso de um autor que tensionou as fronteiras do campo da produção cinematográfica e documentária em um determinado momento, consolidando-se, assim, como figura paradigmática de uma determinada tradição no campo.

\section{Palavras-chave}

Cinema documentário, autoria, Jean Rouch.

\section{Abstract}

The problem of authorship is difficult to address in film studies and especially in the study of documentary. This article proposes the theoretical model of the field of cultural production developed by Pierre Bourdieu as a particularly interesting approach to this issue. First, we discuss some of the key challenges and theoretical problems related to authorship in the documentary. Then, through the analysis of the authorial position of the ethnographer and filmmaker Jean Rouch, the paper shows up briefly the case of an author who strained the boundaries of the field of film and documentary, consolidating thus as a paradigmatic figure of a certain tradition in the field.

\section{Keywords}

Documentary, authorship, Jean Rouch. 


\section{Introdução}

No interior dos estudos cinematográficos, uma das questões talvez mais difíceis de abordar seja a da autoria. A própria natureza artística e ao mesmo tempo industrial da sétima arte costuma constituir o principal complicador dessa questão, na medida em que impossibilita tomar o filme como resultado do trabalho de um único indivíduo. Se, então, pela própria natureza dos meios de produção, o filme é resultado de um trabalho coletivo, poderíamos reduzir o problema da autoria no cinema simplesmente ao dilema de identificar quem seria o principal responsável pelo produto artístico final?

Infelizmente, a questão não é assim tão simples. Em primeiro lugar, porque muito provavelmente não haveria uma única resposta possível, tendo em vista os diferentes modelos que podem ser identificados no panorama da produção cinematográfica mundial. Além disso, é preciso lembrar que a própria ideia de responsabilidade sobre os filmes necessitaria da adoção prévia de critérios de seleção por si só passíveis de questionamento (o autor de cinema seria responsável exatamente pelo quê?).

Frente a esse desafio inicial, defendemos neste artigo uma perspectiva teórica que propõe tratar a questão da autoria no cinema e, mais especificamente, no documentário como construção histórica e social de uma determinada posição no campo da produção (BOURDIEU, 1996). Nesse sentido, não cabe aqui pensar o autor no cinema partindo de uma perspectiva tributária do romantismo, a qual identifica na figura do autor a do gênio criador, sujeito "iluminado" que possui o dom e a liberdade inovadora da criação artística (muito embora essa perspectiva pareça, de alguma forma, estar enraizada no nosso modo de considerar as artes).

No dilema entre possíveis explicações internas ou exclusivamente externas às obras ${ }^{3}$, a perspectiva de análise dos trabalhos culturais defendida 
pelo sociólogo francês Pierre Bourdieu permite um olhar ampliado sobre o campo da produção artística, no qual, resumidamente, obras e autores são analisados a partir de um ponto de vista relacional (BOURDIEU, 1996, p. 62). Nesse sentido, constituir-se autor significa conquistar uma posição de autoria no interior da dinâmica de relações estabelecidas no campo específico de produção. Em outras palavras, tal constituição não se explicaria pela identificação de alguma qualidade essencial de determinado indivíduo, mas sim pela consideração de sua trajetória em um determinado contexto de relações.

Essa perspectiva se mostra especialmente interessante para a análise das questões autorais no campo cinematográfico, ao partirmos da consideração necessária de que a identificação da autoria na figura do diretor do filme não é uma constante na história do cinema (da mesma maneira como não é um ponto pacífico, teoricamente). Essa identificação se tornará regra a partir de um contexto histórico e cultural específico, no qual a figura do diretor pôde conquistar o espaço da autoria.

A tomada dessa posição no campo da produção cinematográfica foi fruto dos embates de jovens críticos franceses que redigiram os "manifestos" da politique des auteurs nos Cahiers du Cinéma, nos anos 50-60. Sintomaticamente, esses "jovens turcos" tornaram-se, posteriormente, realizadores de filmes e, mais do que isso, figuras fundamentais do chamado "cinema de autor"4.

É no interior dessa questão controversa, brevemente delineada, e a partir dessa perspectiva teórica (que se pode definir, sobretudo, como relacional) que o presente artigo pretende abordar o problema da autoria no filme documentário, tendo em vista os complicadores que as particularidades do gênero trazem para essa discussão.

Sendo assim, em um primeiro momento, será discutida a questão específica da autoria no documentário com o objetivo de apontar alguns dos

4 Aqui se abre outra discussão polêmica, que não cabe nos limites deste artigo: a da distinção entre um cinema de arte, visto como reduto de verdadeiros autores, no sentido romântico do termo, e um cinema de grande produção, no qual a própria lógica dessa produção limitaria as possibilidades de autoria. 
principais desafios e problemas teóricos apontados por alguns estudiosos do tema. Aqui cabe ressaltar que não há bibliografia extensa a respeito, tendo em vista que os estudos sobre cinema documentário tomaram força, sobretudo, a partir dos anos de $1990^{5}$. Mesmo assim, considera-se que tais estudos abriram importantes vias de análise e perspectivas fecundas sobre o tema, as quais o presente trabalho de reflexão pretende abordar.

Em um segundo momento do texto, que se poderia considerar como um "estudo de caso", será abordada a figura do antropólogo e cineasta Jean Rouch enquanto um exemplo consagrado de autoria no documentário, assim como na esfera mais ampliada do campo da produção cinematográfica. Nesse momento, o objetivo central será delinear o contexto em que, a partir da conjunção da trajetória do cineasta com o panorama da produção cinematográfica e documentária da época, se consolida a figura "distinta e significativa" do autor Rouch no interior do campo.

\section{A problemática da autoria no documentário}

Pensar a questão da autoria no gênero documentário constitui um desafio se levarmos em conta a problemática da tensão entre objetividade e subjetividade implícita na própria delimitação do gênero. Dizendo de uma maneira bastante genérica6 , diferentemente do filme de ficção, no qual, sob o controle de um diretor, são filmados atores pagos para atuar conforme um roteiro preestabelecido, no documentário, cabe ao cineasta representar o mundo histórico estabelecendo

5 No presente artigo, as referências centrais são Introdução ao documentário (2005), de Bill Nichols - especificamente a definição da "voz do documentário" -, e os artigos reunidos no n.14 da Revue Documentaires (1999), dedicado à problemática da autoria no documentário.

6 Não cabe no escopo deste trabalho abordar a questão controversa da distinção entre documentário e cinema de ficção e dos exemplos de obras que tensionam os limites entre os gêneros. Sendo assim, parte-se do pressuposto da consideração do documentário enquanto gênero distinto, segundo o mesmo ponto de vista adotado por Fernão Ramos: "Ao contrário da ficção, o documentário estabelece asserções ou proposições sobre o mundo histórico. São duas tradições narrativas distintas, embora muitas vezes se misturem [...]. Diferenças entre documentário e fiç̧ão, certamente, não são da mesma natureza das que existem entre répteis e mamíferos. Lidamos com o horizonte da liberdade criativa de seres humanos, em uma época que estimula experiências extremas e desconfia de definições" (RAMOS, 2008, p. 22). 
um corpo a corpo com os sujeitos e as situações filmadas, na aparente ausência de atores profissionais e de um enredo predeterminado.

Parece evidente que essa natureza diversa do modo de produção do documentário possa surgir, a princípio, como um obstáculo para pensar a questão da autoria. Se ao documentarista cabe representar o mundo histórico - que parece acontecer independentemente dele - , como pensar a impressão de uma marca do autor nesse representar?

Pode-se dizer que a questão acima constitui um falso dilema, o qual resulta, por sua vez, de dois "pré-conceitos" correntes. O primeiro deles diz respeito ao filme documentário; o segundo é relativo à própria noção de autoria.

Sobre o documentário, trata-se da visão de que se deve encontrar, nesse gênero de filme, a reprodução da realidade e que, portanto, cabe ao cineasta uma posição estritamente objetiva/neutra frente ao universo filmado. Levado ao extremo, esse preconceito implicaria a supressão do próprio lugar do autor, pois o documentário "puro", ideal, seria aquele no qual o mundo histórico fosse registrado sem qualquer mediação. Ainda que essa perspectiva possa ter orientado determinados modos do fazer documentário (como o modo observativo ${ }^{7}$, as próprias transformações nos modos de representação ocorridas no gênero indicam uma postura cada vez mais autoconsciente do documentário enquanto discurso orientado por um ponto de vista.

Nesse sentido, ainda que possa haver pontos de vista mais ou menos evidentes, mais ou menos complexos ou mais ou menos éticos, o fato de que o documentário é uma forma de representação do mundo, e não uma reprodução do mundo, não pode ser negligenciado. Em Introdução ao documentário, livro de Bill Nichols que é uma das referências no estudo do gênero, a questão da autoria como ponto de vista se encontra delineada, pelo autor, enquanto a "voz" do documentário:

7 Em Introdução ao documentário, distinguem-se seis modos de representação no documentário: poético, expositivo, participativo, observativo, reflexivo e performático (NICHOLS, 2005, p. 62). 
os documentários representam o mundo histórico ao moldar o registro fotográfico de algum aspecto do mundo de uma perspectiva ou de um ponto de vista diferente. Como representação, tornam-se uma voz entre muitas numa arena de debate e contestação social. O fato de os documentários não serem uma reprodução da realidade dá a eles uma voz própria. Eles são uma representação do mundo, e essa representação significa uma visão singular do mundo. A voz do documentário é, portanto, o meio pelo qual esse ponto de vista ou essa perspectiva singular se dá a conhecer (NICHOLS, 2005, p. 73, grifo do autor).

É interessante notar o fato de que, no desenvolvimento da noção de voz, Nichols parece tentar evitar uma abordagem explícita da questão da autoria no documentário, ao fazer a distinção entre um território de "vozes compartilhadas" (características do documentário) e o que seriam as "vozes individuais" do cinema (e que dariam suporte a uma "teoria do autor", mais aplicável ao cinema de ficção) (NICHOLS, 2005, p. 135).

Nesse sentido é que, na sequência do texto, o teórico opta por classificar os diferentes grupos de vozes do documentário em seis modos distintos, ainda que, para proceder às distinções entre os modos, seja necessário recorrer à consideração das características da obra de autores representativos de cada um deles.

Mesmo assim, é possível depreender, em Introdução ao documentário, a aproximação entre autoria e ponto de vista textual. Retomando, então, a definição proposta pelo autor, pode-se concluir que, por meio da identificação do ponto de vista, resultado de uma análise interna da obra, seria possível encontrar a "voz" do filme (e, portanto, o que seria mais próximo de uma marca da autoria). Também vale a pena ressaltar que a própria adoção do termo "voz" parece revelar a necessidade de evitar conotações pessoais e subjetivas e, em última análise, românticas, que estariam vinculadas ao termo "autor", optando por uma abordagem que considera as marcas de sua presença no interior do texto fílmico. 
É exatamente em tais conotações tributárias da noção de autor forjada pelo romantismo que se baseia o segundo preconceito por meio do qual o problema da autoria no documentário costuma ser questionado. Como pensar uma expressão subjetiva de autoria tendo em vista as características do gênero documentário e, sobretudo, as peculiaridades do seu modo de produção?

Especificamente no que diz respeito ao modo de produção, uma objeção recorrente à possibilidade da autoria no filme documentário é o fato de que uma grande quantidade de filmes do gênero é feita "por encomenda" e que, portanto, ao menos nesses casos, não haveria espaço para a autonomia de um sujeito criador.

Boa parte dos artigos reunidos em número especial dedicado à problemática da autoria da Revue Documentaires (n. 14, 1999) discute, exatamente, essa questão. Em "L'auteur face à la commande"8, Gérard Leblanc aponta o fato de que, qualquer que seja a criação audiovisual, ela não pode existir independentemente de um certo conjunto de regras e convenções preestabelecidas, sejam internas (questões referentes ao gênero, por exemplo), sejam externas (condições de produção, possibilidades de financiamento e regras do próprio mercado).

O autor faz uma recuperação da origem romântica da noção de autoria, retomando o momento histórico em que as obras deixaram de obedecer às regras do mecenato, passando à condição de mercadorias. Assim como o mecenas não era considerado o autor da obra, ainda que fosse seu proprietário e tivesse poder de decisão sobre ela, o fato de cineastas produzirem por encomenda não justifica, segundo o autor, a negação da autoria (LEBLANC, 1999, p. 22).

Segundo Leblanc, a liberdade do autor moderno, alardeada pelos próprios autores e por grande parte da crítica frente a esse novo contexto de produção e circulação das obras, mostrou-se ilusória, já que o mecenas transfigurou-se na figura impessoal do mercado. Nesse sentido, ele propõe uma definição de autor que se distancia do paradigma estabelecido no 
romantismo (o qual mais tarde foi "aplicado" pelos "jovens turcos" ao cinema, na politique des auteurs) e que se pode identificar como mais conforme às regras do campo da produção cinematográfica: "O autor não é aquele que ignora tais regras - isso, aliás, seria impossível - nem aquele que as aplica sem questionamento, mas sim aquele que as interpreta de maneira crítica e contribui para transformá-las"9 (LEBLANC, 1999, p. 18).

Se no conceito de "voz" utilizado por Bill Nichols podemos identificar uma abordagem interessante para a questão da autoria no documentário segundo a perspectiva de uma análise interna das obras, é possível perceber que a posição de Leblanc, em certa medida tributária do pensamento de Bourdieu ${ }^{10}$, nos permite abordar essa mesma questão levando em conta os elementos contextuais envolvidos nos processos de constituição da autoria.

Outra questão que chama a atenção no conjunto dos artigos da publicação francesa é que, apesar da quase unanimidade de uma postura crítica frente à noção de autor de cinema erigida nos Cahiers du Cinéma, a preocupação com a defesa do lugar do diretor enquanto o autor do documentário se revela em vários textos ${ }^{11}$.

Considerando o fato de que a maior parte dos autores dos artigos se dedica de alguma forma à realização de documentários, fica evidente, nessa aparente contradição, uma estratégia na luta pela autonomia possível no interior do campo da produção. Simone Vannier, ao identificar, especialmente no domínio televisivo, a ausência do nome do realizador nos créditos dos documentários exibidos, conclui seu artigo da seguinte forma:

9 "L'auteur n'est pas celui qui ignore ces régles - cela serait d'ailleurs impossible - , ni celui qui les applique sans se poser de question, c'est celui qui les interprète de façon critique et contribue à les transformer."

10 Não por acaso, Leblanc cita um trecho de As regras da arte em seu artigo, ainda que afirme que a teoria aplicada de Bourdieu não é suficiente para dar conta de todas as questões envolvidas no campo da produção cinematográfica. 
O que ganhamos ao negar ao autor sua parte, plena de subjetividade e imaginário, reduzindo-o a uma função técnica? Estaríamos apenas acelerando o empobrecimento e a "standartização" que já ameaçam a produção documentária sob o jugo da televisão.

O documentário francês mantém sua vitalidade graças a diversos talentos que devemos encorajar, em vez de nos lançarmos a uma caça às bruxas estéril. Podemos nos orgulhar de sermos o país onde a defesa do autor melhor se exerce: exceção cultural que os artistas do mundo todo invejam e que devemos proteger a todo custo ${ }^{12}$ (VANIER, 1999, p. 46).

Em que pese o tom nacionalista da conclusão, fica claro o posicionamento político orientando o trecho, já que a defesa de uma autoria "à francesa" justificase enquanto estratégia de sobrevivência para autores de documentário que se encontram "em risco de extinção". Em outro artigo, publicado no mesmo número da revista, Michelle Gales retoma a questão, explicitando ainda mais a função estratégica da defesa do autor na produção documentária (GALES, 1999, p. 69).

É preciso notar que o que está em jogo em tais posicionamentos é um autor diverso do gênio romântico, pois está inserido em uma lógica - quer do gênero, quer do mercado - de produção e circulação das obras. É importante ressaltar que a conquista da autoria no campo da produção artística, segundo essa perspectiva, implica tanto a valorização das obras de um autor como a possibilidade de sua sobrevivência no campo. Nesse sentido, sabe-se que o fato de um diretor ser reconhecido como autor de filmes não só influi na recepção de suas obras posteriores como, sobretudo, lhe garante a possibilidade de financiamento para que elas sejam realizadas.

Com relação a essa questão, e no que toca especificamente ao

12 "Que gagnerions-nous à nier la part de l'auteur, riche de sa subjectivité, de son imaginaire, à la réduire à une prestation technique? Nous ne ferions qu'accélérer l'appauvrissement et la standardisation qui déjà menacent la production documentaire, sous l'emprise de la télévision.

Le documentaire français est bien vivant grâce à une brochette de talents que nous devons encorager au lieu de nous livrer à une chasse aux sorcières stérile. Nous pouvons à juste titre nous enorgueillir d'être le pays où la défense de l'auteur s'exerce le mieux: exception culturelle que les artistes du monde entier nous envient et que nous devons à tout prix protéger." 
documentário, não se pode esquecer o fato de que a valorização desse gênero, em termos tanto de público como de crítica, é bem mais recente no interior do campo se comparada à posição hegemônica do filme de ficção. Muito provavelmente, esse contexto pode ser entendido como mais uma das razões para o engajamento percebido nos posicionamentos em defesa da autoria aqui citados.

Delineadas algumas das questões referentes à problemática da autoria no gênero documentário, tentou-se apontar respostas possíveis formuladas por aqueles que se dedicaram ao tema.

Por um lado, aproximar a questão da autoria do conceito de voz, segundo formulado por Nichols, permite uma análise interna dos documentários na qual se evitaria tanto a redução do ponto de vista à expressão/produto da intenção de um sujeito quanto a adoção de um paradigma de neutralidade do documentário que se sabe ser insustentável. Apesar disso, é perceptível certo desconforto do autor de Introdução ao documentário na abordagem da autoria tendo em vista as peculiaridades do filme documentário e, em especial, o compromisso ético do documentarista com a voz do outro.

Nesse sentido, acredita-se que a análise da autoria no documentário como posição no interior do campo da produção permite um viés teórico em que é possível tanto evitar esse desconforto como fornecer uma resposta ao equívoco recorrente de pensar o documentário como espaço da não autoria. Ao contrário, segundo a noção de campo de Bourdieu, pode-se afirmar que os autores de documentários seriam aqueles que, inseridos nas regras do jogo (portanto, atuando em certa conformidade tanto com as convenções do gênero quanto com as possibilidades de produção), conseguem distinguir-se, estabelecendo novas possibilidades no interior do próprio campo. 


\section{O caso Jean Rouch}

Antropólogo, figura fundamental do cinema etnográfico, precursor da Nouvelle Vague, um dos pais do cinéma vérité e do documentário de viés participativo. Traçar a trajetória que levaria à compreensão de todas as posições ocupadas por Jean Rouch em diferentes campos (acadêmico, antropológico, cinematográfico) é tarefa que não cabe nos limites mais estreitos deste artigo.

Sendo assim, conforme o objetivo central, que é o de pensar a autoria no cinema - e, mais especificamente, no documentário - , segundo a noção de campo de produção cultural de Pierre Bourdieu, será necessário adotar um recorte redutor dessa trajetória para que se privilegiem determinados aspectos pertinentes a esse objetivo ${ }^{13}$.

Para tanto, serão apontados certos elementos biográficos, na medida em que eles conformam as escolhas e os caminhos pelos quais a trajetória do cineasta Rouch pôde ser traçada. Além disso, para identificar a posição autoral do realizador segundo uma perspectiva relacional, será necessário compreender essa posição frente aos modos dominantes do fazer cinematográfico e documentário da época, pois é deles que os filmes de Jean Rouch se distinguiram, fazendo com que sua figura de cineasta e documentarista adquirisse relevo no campo.

\section{Notas biográficas e a configuração da trajetória autoral}

Nascido em 31 de maio de 1917, em Paris, Jean Rouch começa a frequentar a cinemateca francesa e o Musée de l'Homme durante o período dos estudos universitários em engenharia (ainda durante esse tempo, frequenta um curso de Marcel Griaule ${ }^{14}$ no Musée de I'Homme). Após se graduar, Rouch e mais dois colegas decidem trabalhar na construção de obras públicas em colônias africanas.

13 Nesse sentido, por exemplo, o lugar de Rouch no campo acadêmico e, especificamente, na antropologia, não será aprofundado. 
Em 1941, ele é enviado ao Níger para trabalhar na construção de estradas de ferro. Nesse primeiro contato, conhece Damouré Zika, que se tornaria, mais tarde, colaborador fundamental em sua obra cinematográfica, além de grande amigo. Como a avó de Damouré era figura central na realização de cerimônias rituais dos songai, Rouch é introduzido nesse universo que se tornará, posteriormente, objeto central de seus estudos em etnografia. Durante essa sua primeira estadia no continente africano, Rouch também é transferido para Dacar, país onde entra em contato com a direção do Institut Français d'Afrique Noir, que lhe permite (e mesmo incentiva) o prosseguimento de suas pesquisas.

Voltando a Paris, em 1944, Rouch inicia seu doutorado sob a orientação de Marcel Griaule, concluindo seus estudos em 1952. Ainda no início do curso (1946), Jean Rouch e mais dois amigos empreendem uma viagem à África com o objetivo de descer o rio Níger em uma canoa. Durante essa aventura, realizam aquele que é um de seus primeiros filmes: Au pays des mages noirs (1947).

Aproximadamente nessa mesma época, ele se torna pesquisador do Centre National de la Recherche Scientifique (CNRS) e, por conta desse trabalho, percorre o Níger e o Mali continuando seus estudos dos rituais songai. Para tanto, prossegue realizando filmes, os quais são considerados como parte integrante de sua pesquisa etnográfica. Em 1949, um desses filmes, Initiation à la danse des possédés, recebe o Grand Prix do Primeiro Festival do Filme Maldito em Biarritz. A respeito dessa primeira consagração, é de fundamental importância considerar o contexto em que tal festival se insere, para que se entenda a trajetória do cineasta no campo:

Esse festival é uma tentativa, da crítica e da cinefilia francesa do pósguerra, de abrir espaço para uma nova produção cinematográfica que começa a ser chamada de "autoral". Por trás do Festival de Biarritz, está o grupo Objectif 49, também presidido por Jean Cocteau, do qual faz parte o núcleo que, dois anos após, em 1951, fundaria a Cahiers du Cinéma: André Bazin e Jacques Doniol-Valcroze, além de Alexandre Astruc, Pierre Kast, René Clément e Claude Mauriac. Nas biografias dos "jovens turcos" da nouvelle vague (Godard, Rivette, Rohmer, Truffaut, 
Chabrol), as noitadas do Festival de Biarritz de 1949 são mencionadas como o momento em que o grupo se delineia, ainda de modo difuso. É evidente que Rouch, ao receber o Grand Prix desse festival do cinema alternativo no pós-guerra, configura-se como referência de primeira linha para a nova geração e para a crítica cinematográfica francesa em geral (RAMOS, 2008, p. 312).

Dessa forma, pode-se dizer que esse primeiro prêmio representa uma espécie de marco inicial no processo de conquista da autoria por Jean Rouch no campo cinematográfico. Outro fato que pode ser citado para corroborar o fato de o realizador ter iniciado sua trajetória como autor a partir de então é que seu curta Au pays des mages noirs (1947) irá ser projetado como complemento nas sessões de Stromboli, filme de 1950, de Roberto Rossellini, um dos autores mais caros à jovem geração dos Cahiers. Paradoxalmente, é no interior da geração dos Cahiers - criticada, posteriormente, por sua visão romantizada do autor de cinema - que Rouch irá obter seus primeiros sinais de consagração ${ }^{15}$.

Alguns anos mais tarde, em 1955, Rouch apresenta, no Musée de l'Homme, Les maîtres fous, registro de uma cerimônia anual dos hauka. Quando da sua primeira exibição, o filme provocou reações de repúdio, porém a articulação peculiar das imagens perturbadoras de possessão com os comentários do cineasta garantiu ao filme um lugar de destaque na filmografia de Jean Rouch, assim como na tradição do filme etnográfico (sobretudo por seu caráter anticolonialista, diverso do viés predominante na época). Vale dizer que, a despeito da diversidade de reações provocadas, Les maîtres fous é premiado na Bienal de Veneza, o que confere mais um sinal de distinção ao realizador.

Pode-se afirmar que esse primeiro período da produção cinematográfica de Jean Rouch, que vai de 1946 até meados dos anos 50, é marcado por documentários mais tradicionais e circunscritos aos limites do registro etnográfico. É na passagem dos anos 50 para os 60 que podemos encontrar os

15 Vale lembrar que, ainda que a visão defendida pelos "jovens turcos" tenha sido duramente atacada, grande parte dos autores erigidos no panteão dos Cahiers é vista, até hoje, como figuras fundamentais no interior do campo cinematográfico. 
filmes fundamentais para a consagração do autor Rouch no campo do cinema ${ }^{16}$. Trata-se do período no qual se elabora a etnoficção desenvolvida pelo cineasta, e que é marcado por filmes com os quais Rouch "provoca uma espécie de virada epistemológica na história do cinema" (RAMOS, 2008, p. 314).

Segundo, ainda, Ramos, Moi, un noir (1958) deve ser considerado como um marco fundamental, a partir do qual a obra do cineasta extrapolaria os limites da representação etnográfica. Considera-se, assim, que grande parte dos procedimentos estilísticos e narrativos identificados e, sobretudo, valorizados como traços distintivos da obra de Jean Rouch a partir de então está potencialmente em evidência em Moi, un noir (como a inovação da improvisação como base do registro documental).

É importante, aqui, abrir parênteses e refletir um pouco mais sobre a importância de considerar a conquista da autoria inserida em um contexto de relações. Nesse sentido, ainda que traços semelhantes aos valorizados na obra de Rouch possam ser identificados no trabalho de outros documentaristas e cineastas (e que muitos desses traços tenham se tornado representativos de certa tradição documentária desde então), o fato de Rouch ter sido identificado como pioneiro no momento específico da emergência dos cinemas novos para os quais ele se tornou referência concorreu para que sua figura como autor adquirisse distinção na história do cinema. Nesse sentido, pode-se dizer que o caso de Jean Rouch configura um exemplo típico de autor que tensionou as fronteiras e as convenções inscritas no campo, contribuindo para sua transformação em um determinado momento.

Ainda do ponto de vista dos filmes tidos como fundamentais no amplo conjunto das realizações do autor $^{17}$, parece curioso que a obra de maior

16 Entre esses marcos, estão os filmes Jaguar (1957-1967), La chasse au lion à l'arc (1957-1964), Moi, um noir (1958) e La pyramide humaine (1959).

17 Vale lembrar que Jean Rouch realizou mais de uma centena de filmes. Contudo, é interessante notar que o processo de constituição da autoria pode ser traçado no percurso de menos de uma dezena de filmes do cineasta, realizados, sobretudo, a partir do final dos anos de 1950. 
consagração na carreira de cineasta e documentarista de Jean Rouch, Chronique d'un été (1960), seja um filme realizado em parceria. Fruto de um projeto concebido pelo sociólogo Edgar Morin, o filme ocupa destaque na história do documentário enquanto marco inaugural de uma nova forma narrativa, que irá influenciar diretamente as estratégias adotadas pelos cinemas novos. Inicialmente denominada de cinéma vérité, essa nova forma está diretamente ligada a um momento fundamental no desenvolvimento das tecnologias de registro da imagem e do som no cinema - desenvolvimento esse em que Rouch participou ativamente:

\begin{abstract}
Além do som na tomada, o direto pede o desenvolvimento de uma câmera que permita o deslocamento livre do fotógrafo. Isso ocorre pioneiramente na França, através do trabalho de André Coutant, não sob a pressão da televisão (como nos Estados Unidos), mas atendendo a demandas da comunidade etnológica (Comitê do Filme Etnológico do Musée de l'Homme) e cinematográfica. [...] O aparecimento do primeiro "grupo sincrônico ligeiro" na França, segundo Ruspoli, tem suas origens no Comitê Internacional do Filme Etnológico e Sociológico no Museu do Homem de Paris, evoluindo a partir da figura de Jean Rouch e seu encontro com André Coutant, em 1960 (RAMOS, 2008, p. 283).
\end{abstract}

Mais uma vez, percebe-se que é sempre em relação a um contexto específico de relações e representações dominantes na época que a posição "inovadora" do cineasta se afirma e pode ser valorizada. Diferentemente do paradigma do autor "gênio", a singularidade do autor, nessa perspectiva, não é negada, porém está vinculada a todo um quadro de possibilidades presente em determinado momento, com o qual se relaciona a posição do cineasta.

Pode-se dizer, então, que a conquista da posição de autor por Rouch no campo se inscreve, como bem definido por Leblanc, no encontro entre "as representações socialmente instituídas e sua trajetória" (LEBLANC, 1999, p. 6), em um espaço em que a subjetividade do cineasta encontrou sua expressão possível frente às relações postas, naquele momento, no interior do campo relações que tal expressão pôde tensionar. 
No decorrer de sua trajetória como autor já consagrado, a partir dessa virada entre os anos de 1950 e 1960, Rouch realiza uma obra extremamente prolífica e multifacetada, que resiste, por vezes, a definições. Em número dedicado a Jean Rouch pela revista CinémAction ("Jean Rouch ou Le cinéplaisir"), René Prédal inicia o prólogo afirmando que:

o trabalho de Jean Rouch produziu o oposto de uma carreira linear ou daquilo que gostamos de considerar como a obra de um autor: é uma criação prolífica, multiforme, irregular, por vezes subterrânea, para depois se oferecer à luz da fama; uma célula-mãe que prolifera, uma matéria rizomática que engendra prolongamentos por vezes inesperados, mas sempre duradouros ${ }^{18}$ (PRÉDAL, 1996, p. 12).

Contudo, segundo a perspectiva aqui adotada, a autoria não se constrange a uma unidade orgânica e coerente na qual se espelha o indivíduo. Se assim fosse, como se justificaria a organização, pelo próprio René Prédal, de uma publicação reunindo artigos sobre Jean Rouch, a não ser por sua posição autoral no campo?

\section{Das conclusões possíveis}

Frente aos objetivos traçados inicialmente neste artigo, é possível pensar alguns dos alcances e limites da consideração do autor de cinema e documentário segundo a perspectiva do campo de produção cultural de Pierre Bourdieu.

Em primeiro lugar, ao abordar algumas das questões pertinentes à problemática da autoria no cinema e, sobretudo, no filme documentário, acreditase que a opção por essa perspectiva teórica permite responder satisfatoriamente aos principais obstáculos que frequentemente são impostos à consideração da autoria nesses domínios. Nesse sentido, o fato de os produtos audiovisuais

18 "le travail de Jean Rouch a produit tout le contraire d'une carrière linéaire ou de ce que l'on aime à considerer comme une oeuvre d'auteur: c'est une création prolifique, multiforme, irrégulière, tour à tour souterraine puis offerte un temps aux clartés de la renomée, une cellule mère qui essaime, une matière rhizomatique qui engendre des prolongements souvent innatendus, mais toujours vivaces." 
serem fruto de um trabalho coletivo (ou mesmo de que sua realização seja constrangida às exigências do mercado, ou da encomenda) não impossibilita a adoção de uma perspectiva autoral tomada enquanto posição no interior do campo. Sendo assim, pode-se dizer que essa perspectiva teórica constitui-se numa estratégia metodológica produtiva para a consideração da autoria, em especial no domínio que aqui nos interessa.

Contudo, pode-se afirmar que a importância dessa perspectiva de análise não se restringe apenas a sua "operacionalidade". Nesse sentido, acredita-se que a consideração, ainda que breve, do caso específico de Jean Rouch pôde oferecer um bom exemplo da pertinência da teoria proposta por Pierre Bourdieu no enfrentamento da questão autoral.

Pode-se dizer que o autor Jean Rouch mostrou-se exemplar para esse tipo de análise, tanto pela imbricação de sua emergência no campo em um contexto de transformações tecnológicas, críticas e discursivas quanto por sua dupla articulação, quer no campo do cinema, quer nos limites específicos do documentário (em um gênero no qual a figura do diretor do filme como autor ainda hoje se apresenta vulnerável). Acredita-se que a compreensão dos elementos em jogo nessa dupla articulação só se pode cumprir, efetivamente, por meio da adoção de uma perspectiva contextual e relacional como a proposta por Bourdieu, segundo a qual o autor sempre se afirma "em relação a".

Outra questão delicada à qual a perspectiva de autoria aqui adotada também permite responder é, para além da autoria como originalidade, a da autoria vista como unidade e coerência (e que está no fundamento de análises autorais centradas na identificação das recorrências temáticas e de estilo na obra de um determinado autor). O principal problema, em tais análises, é como lidar, por exemplo, com os elementos e as obras de um mesmo autor que "escapam" ou mesmo se opõem aos traços distintivos que se costuma atribuir a ele. A noção de autor que orienta essa perspectiva acaba mesmo por redundar em uma espécie de paradoxo: se, por um lado, reivindica-se do autor a originalidade, por outro lado, como se espera que ele seja uno? 
No caso específico da trajetória de Jean Rouch, aqui analisada, fica evidente o fato de que o processo de conquista da posição autoral está circunscrito a um período específico de sua carreira, vinculado a um número reduzido de filmes - frente à extensa e variada produção do cineasta. Nesse sentido, o autor se afirma independentemente da multiplicidade de sua obra, pois aquilo que define a autoria está vinculado muito mais às condições de coexistência (recepção e circulação) dos filmes no interior do campo, do que a uma essência reconhecível em seus filmes.

Contudo, a perspectiva relacional de Bourdieu parece nos propor um desafio. É evidente que tal perspectiva de análise permite dar conta, com muita propriedade, dos elementos externos com os quais as obras e os autores se relacionam (ainda que o sociólogo francês afirme poder conciliar as principais exigências de abordagens internas e externas das obras com seu método). Mesmo na análise primorosa de $A$ educação sentimental, de Flaubert, em As regras da arte, esse ideal de conciliação entre as duas perspectivas de análise não chega a se cumprir totalmente. Talvez esse possa ser apontado como o principal limite dessa perspectiva, restando aos analistas que adotarem a concepção de autoria tal qual forjada por Bourdieu o desafio de cumprir com a análise das obras de um autor sem perder de vista a dinâmica das relações presentes no campo. 


\section{Referências}

ASTRUC, A. "Nascimento de uma nova vanguarda: a 'caméra stylo'". In: OLIVEIRA, M. (Org.). Nouvelle Vague. Lisboa: Cinemateca Portuguesa-Museu do Cinema, 1999.

BAZIN, A. "De la política de los autores". In: BAECQUE, A. de (Org.). La política de los autores: manifesto de una generación de cinéfilos. Barcelona: Paidós Ibérica, 2003.

BOURDIEU, P. As regras da arte: gênese e estrutura do campo literário. Lisboa: Editorial Presença, 1996.

. Razões práticas: sobre a teoria da ação. Campinas: Papirus, 1996.

GALES, M. "L'auteur du crime". Revue Documentaires, n. 14, 1. trim. 1999.

L'AUTEUR em questions. Revue Documentaires, n. 14, 1. trim. 1999.

LEBLANC, G. "L'auteur face à la commande". Revue Documentaires, n. 14, 1. trim. 1999.

NICHOLS, B. Introdução ao documentário. Campinas: Papirus, 2005.

PRÉDAL, R. "Prólogo". CinémAction, n. 81, 4. trim. 1996.

RAMOS, F. P. Mas afinal... o que é mesmo documentário? São Paulo: Senac, 2008.

- (Org.). Teoria contemporânea do cinema: v. 2: documentário e narratividade ficcional. São Paulo: Senac, 2005.

TRUFFAUT, F. "Uma certa tendência do cinema francês". In: OLIVEIRA, M. (Org.). Nouvelle Vague. Lisboa: Cinemateca Portuguesa-Museu do Cinema, 1999.

VANNIER, S. "Nouvelle chasse aux sorcières". Revue Documentaires, n. 14, 1. trim. 1999. 